\title{
Improved parameter fitting for models of young and aged neurons
}

\author{
Christina M Weaver $^{1 *}$, Aniruddha Yadav², Patrick R Hof ${ }^{2}$, Jennifer I Luebke ${ }^{3}$ \\ From Twentieth Annual Computational Neuroscience Meeting: CNS*2011 \\ Stockholm, Sweden. 23-28 July 2011
}

The parameters of neuronal compartment models must be determined carefully in order to match experimental data. Optimization algorithms can simplify this task by automatically searching the multidimensional parameter space to identify combinations of parameters that best fit experimental data, as measured by a fitness function that represents salient differences between simulated and experimental data. The success of automated parameter fitting depends critically on many issues, including the choice of parameters selected for fitting, the parameter search method, and the design of the fitness function. Previously we developed a fitness function that explicitly quantifies the shape of action potentials and afterhyperpolarizations [1], and the time-varying firing rate [2].

The present project arises from our study of neocortical pyramidal cells from young and aged rhesus monkeys in vitro [3]. In response to current clamp protocols that evoked action potentials, aged neurons fired at significantly higher rates than young ones did. Yet, both young and aged neurons displayed an initial fast phase of firing rate adaptation followed by a slower one. Neither parameter optimization with our existing fitness function, nor the popular phaseplane method [4], sufficiently captured the two-phase adaptation.

We have extended our fitness function to fit firing rate time series with two single exponentials, separated by an automatically-chosen cutoff. The fitness function also includes a term to quantify action potential backpropagation, whereby voltage decays approximately exponentially with distance from the soma [5]. The fitness function is designed for use with NEURON, with

\footnotetext{
* Correspondence: christina.weaver@fandm.edu

'Department of Mathematics, Franklin and Marshall College, Lancaster, PA 17603, USA

Full list of author information is available at the end of the article
}

the parameter search guided by MATLAB's Global Optimization Toolbox. We used the fitness function and search method to optimize morphologically accurate compartmental models of young and aged neurons to their respective physiological data. We compared results from our original and improved fitness functions against the phase-plane fitness function, separately optimizing either ion channel densities or channel kinetics. All searches identified multiple combinations of parameters that fit the data, with our new fitness function having the best qualitative matches to empirical data. These parameter fits will be used to identify biological mechanisms that may be responsible for the physiological differences between young and aged neurons.

\section{Acknowledgements \\ The project described was supported by NIH/NIA: R01-AG035071; R01- AG025062 and P01-AG00001.}

\section{Author details}

'Department of Mathematics, Franklin and Marshall College, Lancaster, PA 17603, USA. ${ }^{2}$ Department of Neuroscience and Friedman Brain Institute, Mount Sinai School of Medicine, New York, NY 10029, USA. ${ }^{3}$ Department of Anatomy and Neurobiology, Boston University School of Medicine, Boston, MA 02118, USA.

Published: 18 July 2011

\section{References}

1. Weaver CM, Wearne SL: The role of action potential shape and parameter constraints in optimization of compartment models. Neurocomputing 2006, 69:1053-1057.

2. Weaver CM, Wearne SL: Neuronal firing sensitivity to morphologic and active membrane parameters. PLoS Comput Biol 2008, 4:130-150.

3. Chang YM, Rosene DL, Killiany RJ, Mangiamele LA, Luebke J: Increased action potential firing rates of layer $2 / 3$ pyramidal cells in the prefrontal cortex are significantly related to cognitive performance in aged monkeys. Cerebral Cortex 2005, 15:409-418.

4. LeMasson G, Maex R: Introduction to equation solving and parameter fitting. In Computational Neuroscience: Realistic Modeling for Experimentalists. Boca Raton, FL: CRC Press;Schutter ED 2000:
C Biomed Central

C 2011 Weaver et al; licensee BioMed Central Ltd. This is an open access article distributed under the terms of the Creative Commons Attribution License (http://creativecommons.org/licenses/by/2.0), which permits unrestricted use, distribution, and reproduction in any medium, provided the original work is properly cited. 
5. Waters J, Schaefer A, Sakmann B: Backpropagating action potentials in neurones: measurement, mechanisms and potential functions. Prog Biophys Mol Biol 2005, 87:145-170.

doi:10.1186/1471-2202-12-S1-P207

Cite this article as: Weaver et al:: Improved parameter fitting for models of young and aged neurons. BMC Neuroscience 2011 12(Suppl 1):P207.

Submit your next manuscript to BioMed Central and take full advantage of:

- Convenient online submission

- Thorough peer review

- No space constraints or color figure charges

- Immediate publication on acceptance

- Inclusion in PubMed, CAS, Scopus and Google Scholar

- Research which is freely available for redistribution

Submit your manuscript at www.biomedcentral.com/submit

() BioMed Central 